\title{
ECONOMETRIC ANALYSIS OF OIL CONSUMPTION AND ECONOMIC GROWTH IN NEPAL
}

\author{
Tara Prasad Bhusal*
}

\begin{abstract}
Oil is one of the main inputs for many sectors like transportation, manufacturing, electricity generation and others. Oil is also very important for the economic growth of Nepal. This paper examines the short and long-run causality between oil consumption and Gross Domestic Product for Nepal using annual data covering the period of 1975-2009. Granger causality test is employed to analyse the relationship between economic growth and oil consumption variables with same order of integration (I (1)). In this study is found that there exists bi-directional Granger causality between oil consumption and economic growth in the short and long run.
\end{abstract}

Key words: Oilconsumption, Economic Growth, Causality, Co-integration

\section{INTRODUCTION}

Oil now constitutes a critical factor in sustaining the well-being the Nepal's as well as the nation's economic growth. Production in industries such as manufacturing, transportation, and electricity generation demands a substantial amount of oil. Therefore, oil- supply side measures in harmony with economic growth are needed. In addition to supply side measures, demand side management measures are also needed. The oil intensity in Nepal is much larger than those in the developed countries. High oil intensity in Nepal reflects inefficient oil usage in industries and/or agriculture and indicates that there are high oil-saving potentials. Thus, improving oil consumption efficiency of automobiles and machines and introducing various kinds of tariff reforms aiming to control oil consumption patterns through levelling projected oil demand and saving supply costs of oil can induce a high degree of efficiency in the existing facilities without adversely affecting a high level of oil consumption for economic growth.

The direction of causality between energy consumption and economic growth has significant policy implications for countries, enjoying implicit generous subsidies (low domestic prices) for energy. If, for example, there exists unidirectional Granger causality running from income to energy, it may be implied that energy conservation policies such as phasing out energy subsidies or elimination of energy price distortions have little ad- verse or no effects on economic growth. On the other hand, if unidirectional causality runs from energy consumption to income, reducing energy consumption, for example through bringing domestic energy prices in line with market prices, could lead to a fall in income and employment. And lastly, no causality

\footnotetext{
* Mr. Bhusal is Lecturer at the Department of Economics, Patan Multiple Campus, Tribhuvan University
} 
in either direction would indicate that policies for increasing energy consumption do not affect economic growth (Mehrara, 2007:2940).

In the past two decades, numerous studies have been conducted to examine the relationship between energy consumption and economic growth. The overall findings show that there is a strong relationship between energy consumption and economic growth. For example, Kraft and Kraft (1978), Ghosh (2002), and Mozumder and Mozumder (2009) found unidirectional causality running from GDP to energy consumption. Shiu and Lam (2007) reported unidirectional causality running from energy consumption to GDP. Jumbe (2004) found bidirectional causality between energy consumption and GDP. However, Akarca and Long (1980), Erol and Yu (1987a), Yu and Choi (1985), and Yu and Hwang (1984) found no causal relationship between GDP and energy consumption. Recently, Yang (2000) found unidirectional causality running from economic growth to coal con- sumption in Taiwan. Yoo (2006) found unidirectional long-run causality from economic growth to coal consumption, and bidirectional strong causality from coal consumption to economic growth in Korea.

In a summary of the literature on the causal relationship between energyconsumption including oil consumption, and economic growth, there are a number of evidences to support bi-directional or unidirectional causality between energy consumption and economic growth. Despite the expanding literature on the study of causal relationships between energy consumption and economic growth, to the best of the author's knowledge, there have been only a few studies specifically addressing the causal relationship between oil consumption and economic growth. Recently, Yang (2000a) investigated the causal relationship between real gross domestic product (GDP) and several disaggregate categories of energy consumption, including coal, oil, natural gas, and electricity, and found that there is unidirectional causality running from economic growth to oil consumption in Taiwan without any feedback effect (Yoo, 2006: 235).

The purpose of this paper is, therefore, to investigate the causality between oil consumption and economic growth, and to obtain policy implications from the results.

\section{ECONOMETRIC METHODOLOGY}

\section{ADF Unit Root Test}

Many macroeconomic time series contain unit roots dominated by stochastic trends, as developed by Nelson and Plosser (1982). Unit root tests are important in examining the stationarity of a time series because a nonstationary regressor invalidates many standard empirical results and thus requires special treatment. Granger and Newbold (1974) have found by simulation that the F-statistic calculated from the regression involving the non- stationary time-series data does not follow the Standard distribution. This nonstandard distribution has a substantial rightward 
shift under the null hypothesis of no causality. Thus the significance of the test is overstated and a spurious result is obtained, Bhusal (2009). The presence of a stochastic trend is determined by testing the presence of unit roots in time- series data. Non-stationarity or the presence of a unit root can be tested using the Dickey and Fuller (1981) tests.

The test is the $t$ statistic on $\phi$ in the following regression:

$\Delta Y_{t}=\alpha_{0}+\alpha_{01 . t}+\varphi Y_{t-1}+\sum \psi i \Delta y_{t-i}+\varepsilon_{t}$

\section{Tests of Cointegration}

The cointegration test is based in the methodology developed by Johansen (1991), and Johansen and Juselius (1993). Johansen's method is to test the restrictions imposed by cointegration on the unrestricted variance autoregressive, VAR, involving the series.

The mathematical form of a VAR is

$y_{t}=A_{1} y_{t-1}+\ldots \ldots \ldots \ldots \ldots+A_{p} y_{t-p}+B x_{t}+\varepsilon_{t}$

where $y_{t}$ is an $n$-vector of non-stationary I(1) variables, $x_{t}$ is a $d$-vector of deterministic variables, $A 1, . ., A_{p}$ and $B$ are matrices of coefficients to be estimated, and $i t$ is a vector of innovations that may be contemporaneously correlated with each other but are uncorrelated with their own lagged values and other right-hand side variables. We can rewrite the VAR as Equation (3):

$$
\Delta \mathrm{y}_{\mathrm{t}}=\Pi \mathrm{y}_{\mathrm{t}-1}+\sum \mu_{\mathrm{i}} \Delta \mathrm{y}_{\mathrm{t}-\mathrm{i}}+\beta \mathrm{x}_{\mathrm{t}}+\mathrm{u}_{\mathrm{t}}
$$

where, $\quad \Pi=\sum \mathrm{A}_{\mathrm{i}-} \mathrm{I}_{\mathrm{t}}, \quad \mu_{\mathrm{i}}=-\sum \mathrm{A}_{\mathrm{j}}$

Granger's representation theorem asserts that if the coefficient matrix $\mathrm{n}$ has reduced rank $\mathrm{r}<\mathrm{n}$, then there exist $n \times r$ matrices $\alpha$ and $\beta$ each with rank $\mathrm{r}$ such that $\Pi=\alpha$ $\beta^{\mathrm{T}}$ and $\beta^{\mathrm{T}} \mathrm{yt}$ is stationary. Here, $r$ is the number of co-integrating relations and each column of $\beta$ is a co-integrating vector. For $n$ endogenous non-stationary variables, there can be from (0) to $(n-1)$ linearly independent, cointegrating relations Yin and Xu (2003: 307).

\section{Error Correction Modelling (ECM)}

The existence of co-integration relationships indicates that there are long-run relationships among the variables, and thereby Granger causality among them in at least one direction. The ECM was introduced by Sargan (1964), and later popularized by Engle and Granger (1987). It is used for correcting disequilibrium and testing for long and short- run causality among co-integrated variables. The ECM used in this paper is specified as follows; 


$$
\begin{aligned}
& \Delta \mathrm{OIL}_{\mathrm{t}}=\mathrm{a}_{0}+\sum_{i=1}^{m} a_{1 \mathrm{i}} \Delta \mathrm{OIL}_{\mathrm{t}-\mathrm{i}}+\sum_{\mathrm{i}=1}^{n} a_{2 \mathrm{i}} \Delta \mathrm{GDP}_{\mathrm{t}-\mathrm{i}}+\lambda \mathrm{ECM}_{\mathrm{t}-1}+\mathrm{u}_{\mathrm{t}} \\
& \Delta \mathrm{GDP}_{\mathrm{t}}=\mathrm{b}_{0}+\sum_{i=1}^{m} b_{1 \mathrm{i}} \Delta \mathrm{GDP}_{\mathrm{t}-\mathrm{i}}+\sum_{i=1}^{n} b_{2 \mathrm{i}} \Delta \mathrm{OIL}_{\mathrm{t}-\mathrm{i}}+\theta \mathrm{ECM}_{\mathrm{t}-1}+\varepsilon_{\mathrm{t}}
\end{aligned}
$$

where $\Delta$ is the difference operator, $\mathrm{m}$ and $\mathrm{n}$ are the numbers of lags, a's and b's are parameters to be estimated and, $\lambda$ and $\theta$ are the error correction term, which is derived from the long run co-integration relationship.

In each equation, change in the endogenous variable is caused not only by their lags, but also by the previous period's disequilibrium in level. Given such a specification, the presence of short and long-run causality could be tested (Shiu and Lam, $2010: 50$ ).

\section{DATA AND EMPIRICAL RESULTS}

\section{Data}

The data used in this study consist of annual time series of GDP and oil consumption for Nepal 1975 to 2009. The GDP and Oil consumption data were obtained from the Economic Survey (MOF) of Nepal. GDP: Gross Domestic Product (Rs Million) and OIL: Oil Consumption (Kilo Litres). The following Figure 1 and 2, respectively, describes oil consumption and GDP of Nepal over the period of 1975-2009 (Economic Survey,2009/10).

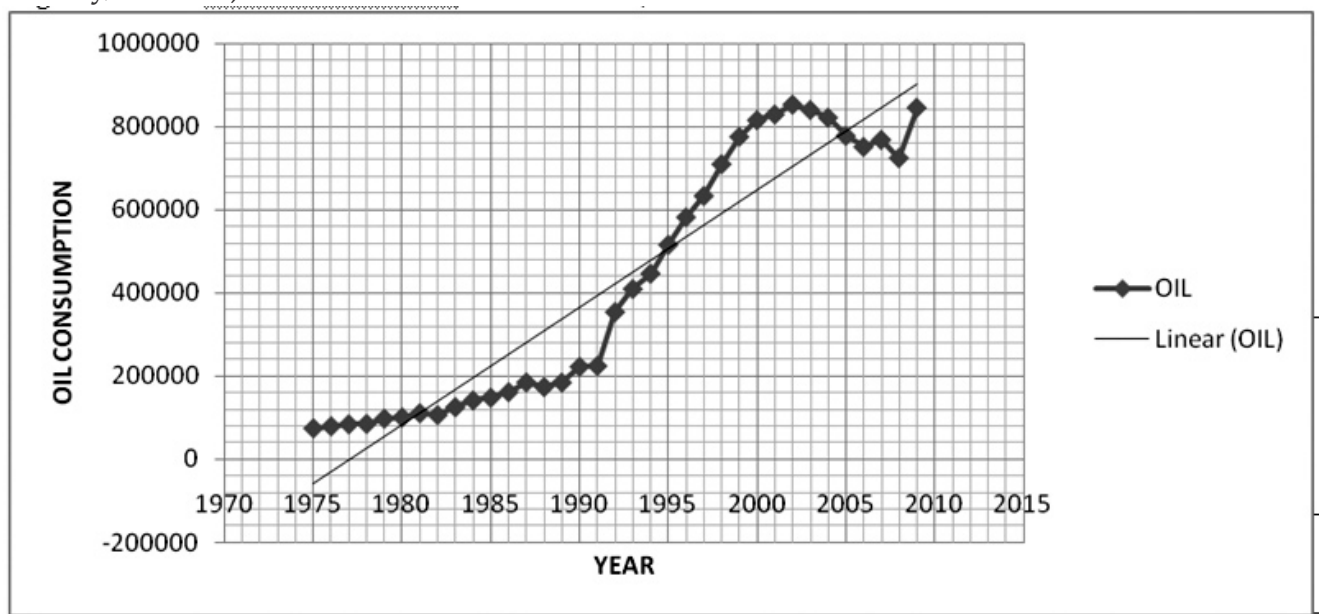

Figure 1: OIL CONSUMPTION(in Kilo Litres) 


\section{Figure 2: GDP GROWTH TREND (in RS 10 Millions)}

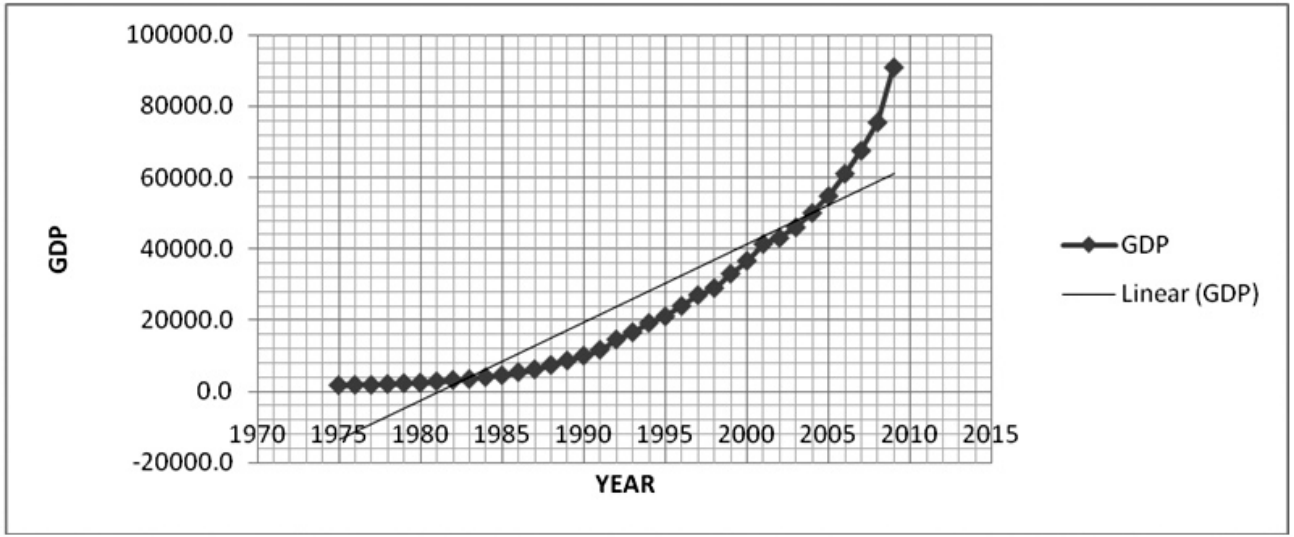

\section{Result of Unit Roots}

The results of the unit root tests for the series of OIL and GDP variables are shown in Table 1. The ADF test provides the formal test for unit roots in this study. The p-values corresponding to the ADF values calculated for the two series are larger than 0.05 . This indicates that the series of all the variables are non-stationary at $5 \%$ level of significance and thus any causal inferences from the two series in levels are invalid.

Table 1. Results of ADF Test for Unit Roots According to Level

\begin{tabular}{|c|c|c|}
\hline Variables & Intercept & CV(LL) \\
\hline OIL & -31337.04 & -3.56 \\
\hline GDP & -242.69 & -2.95 \\
\hline
\end{tabular}

* CV stands for critical values, which are at the 5\% level. The critical values are calculated from MacKinnon. LL stands for lag length. The lag lengths are selected using the AIC criterion.

The analysis of the first differenced variables shows that the ADF test statistics for all the variables are less than the critical values at $5 \%$ levels (Table 2). The results show that all the variables are stationary after differencing once, suggesting that all the variables are integrated of order I (1). 
Table 2. Results of ADF Test for Unit Roots According to First Difference

\begin{tabular}{|c|c|c|}
\hline Variables & Intercept & CV(LL) \\
\hline$\Delta$ OIL & 8495.039 & -3.557759 \\
\hline$\Delta$ GDP & -159.9027 & -3.552973 \\
\hline
\end{tabular}

* CV stands for critical values, which are at the 5\% level. The critical values are calculated from MacKinnon. LL stands for lag length. The lag lengths are selected using the AIC criterion.

As indicated, the basic idea behind cointegration is to test whether a linear combination of two individually non-stationary time series is itself stationary. Given that integration of two series is of the same order, it is necessary to test whether the two series are cointegrated over the sample period. The results of the Johansen cointegration test for the series OIL and GDP are reported in Table 3.

Table 3.Results of Johansen's Cointegration Test

\begin{tabular}{|l|l|l|l|}
\hline Null Hypotheses $\mathrm{H}_{\mathrm{o}}$ & Alternative ypotheses $\mathrm{H}_{1}$ & Trace Statistic & Critical Value (5\%) \\
\hline $\mathrm{r}=0$ & $\mathrm{r}=1$ & 47.215461 & 25.87210 \\
\hline $\mathrm{r} \leq 1$ & $\mathrm{r}=2$ & 21.603219 & 12.51798 \\
\hline
\end{tabular}

The likelihood ratio tests show that the null hypothesis of absence of cointegrating relation $(r=0)$ can be rejected at $5 \%$ level of significance, and that the null hypothesis of existence of at most one cointegrating relation $(r \leq 1)$ can be rejected at $5 \%$ level of significance. We can see that both tests suggest the existence of two cointegrating vectors driving the series with two common stochastic trends in the data. Thus, we can conclude that oil consumption and GDP are cointegrated. That is, there is a longrun relationship between oil consumption and GDP for Nepal.

\section{Results of Error-Correction Model}

If the series of two variables are non-stationary and the linear combination of these two variables is stationary, then the error correction modeling rather than the standard Granger causality test should be employed. Therefore, an ECM was set up to investigate both short-run and long-run causality. In the ECM, first difference of each endogenous variable (GDP and OIL) was regressed on a period lag of the cointegrating equation and lagged first differences of all the endogenous variables in the system, as shown in Equations (5) and (6). The results of error correction model are presented in Table 4 . 


\section{Table 4. The Result of Error Correction Model}

\begin{tabular}{|l|c|c|c|}
\hline $\mathrm{H}_{\mathrm{o}}$ & Lag Lengths & F Statistics & $\mathrm{t}$ statistics for $\mathrm{ECM}_{\mathrm{t}-1}$ \\
\hline$\Delta$ GDP- $\triangle$ OIL & $\mathrm{m}=1 \mathrm{n}=1$ & $1.788883^{*}$ & $-1.24034^{*}$ \\
\hline$\Delta$ OIL- $\triangle$ GDP & $\mathrm{m}=2 \mathrm{n}=2$ & $53.29368^{*}$ & $-1.35141^{*}$ \\
\hline
\end{tabular}

Notes: The lag lengths are chosen by using AIC information criterion. * Denotes the rejection of the null hypothesis at $5 \%$ level of significance.

According to results of the Table 4, short-run causality is found to run from oil consumption to GDP. In addition, the reverse short-run causality also exits. That is, there is bidirectional short-run Granger-causality oil consumption and economic growth. The coefficient of the ECM is found to be significant in Equations (5) and in equation (6), which indicates, that exists bidirectional Granger causality between oil consumption and economic growth in long run.

\section{CONCLUSION}

This paper has investigated the ECM model to examine the causal relationship between oil consumption and GDP in Nepal using the annual data covering the period of 1975-2009. Prior to testing for causality, the ADF test and Johansen maximum likelihood test were used to examine for unit roots and cointegration. Our estimation results indicate that there are bidirectional short-run causality between oil consumption and economic growth, bidirectional long-run causality between economic growth and oil consumption.

Oil consumption could be thought of as a leading factor of the economy in the short run as well as in the long run. The basic reason for this may be that the enormous use of oil mostly in the industry and transportation sector has directly pushed the economy. Production in industries such as manufacturing, construction and transportation demands a substantial amount of oil. Consequently increased oil consumption also directly affects employment. In conclusion, for the developing countries in general, oil is an important ingredient of economic development. On the other hand, reducing oil consumption could lead to fall in income and employment.

\section{References}

Akarca, A.T. and Long, T.V. (1980). On the relationship between energy and GDP: a reexamination, J.Energy Dev, 5, 326-331.

Bhusal, Tara Prasad (2009). Basic Econometrics, Ayam Publication, Kathmandu. 
Chang, T. Fang, W and Wen, L.F. (2001). Energy consumption, employment, output, and tempo- ral causality: evidence fromTaiwan based on cointegration and errorcorrection modelling techniques, Applied Economics, 33, 1045-1056.

Dickey, D.A. and Fuller, W.A., (1981). Likelihood ratio statistics for autoregressive time series with a unit root, Econometrica, 49, 1057-1072.

Economic Survey (2009/10). Ministry of Finance, Government of Nepal.

Engle, R. F. and Granger, C. W. J. (1987), Cointegration and error correction: representation, estimation, and testing, Econometrica, 55, 251-276.

Erol, U. and Yu, E.S.H. (1987a). Time series analysis of the causal relationships between US energy and employment, Resources Energy, 9, 75-89.

Granger, C. and Newbold, P. (1974). Spurious regressions in econometrics, J. Econometrics 2,111-120.

Ghosh, S. (2002). Electricity consumption and economic growth in India, Energy Policy, 30,125-129

Johansen, S. (1991). Estimation and hypothesis testing of cointegration vectors in Gaussian vector autoregression models, Econometrica, 59, 1551-1580.

Johansen, S. and Juselius, K. (1993). Testing structural hypotheses in a multivariate cointegration analysis of the PPP and the UIP for UK, Journal of Econometrics, 53, 211-244.

Jumbe, C. B.L. (2004). Cointegration and causality between electricity consumption and GDP: empirical evidence from Malawi, Energy Econ. 26, 61-68.

Kraft, J. and Kraft, A. (1978). On the relationship between energy and GDP, J. Energy Dev. 3,401-403.

Mackinnon, J. (1991). Critical values for cointegration tests, longrun economic relationships reading, in Cointegration (Ed.), Oxford University Press, New York, 267- 76.

Mehrara, M. (2007). Energy consumption and economic growth: The case of oil exporting countries", Energy Policy, 35, 2939-2945.

Mozumder, P. Marathe, A. (2009). Causality relationship between electricity consumption and GDP in Bangladesh, Energy Policy, 35 (1) pp.395402.

Nelson, C. R. and Plosser, C. I. (1982). Trends and random walks in macroeconomic time series- some evidence and implications, Journal of Monetary Economics, 10, 139- 162.

Shiu, A.L. and Lam, P.L (2010). Electricity consumption and economic growth in China. Energy Policy, 32, pp. 47-54.

Yu, E.S.H. and Choi, J.Y. (1985). The causal relationship between energy and GDP: an international comparison, J. Energy Dev. 10, 249-272. 
Yu, E.S.H. and Hwang, B.K. (1984) The relationship between energy and GDP: further results, Energy Econ. 6, 186-190.

Yoo, S.H. (2006). Causal relationship between coal consumption and economic growth in Korea, Applied Energy, 83, 1181-1189

Yang, H.Y. (2000). Coal Consumption and Economic Growth in Taiwan, Energy Sources, 22, 109-115.

Yang, H.-Y. (2000a). A note on the causal relationship between energy and GDP in Taiwan. En-ergy Economics 22, 309-317.

Yin, R. and $\mathrm{Xu}, \mathrm{J}$. (2003). Identifying the inter-market relationships of forest products in the Pacific Northwest with cointegration and causality tests, Forest Policy and Economics, 5, 305-315.

Yoo, S.E. (2007). Oil Consumption and Economic Growth: Evidence from Korea, Energy Source. 